\title{
THE EMERGENCE OF AN AMPLIFIED MINDSET OF DESIGN: IMPLICATIONS FOR POSTGRADUATE DESIGN EDUCATION
}

\author{
MAFALDA MOREIRA, EMMA MURPHY, IRENE MCARA-MCWILLIAM \\ THE GLASGOW SCHOOL OF ART \\ Corresponding author: mafalda.moreira@gmail.com
}

\section{ABSTRACT}

In a global scenario of complexity, research shows that emerging design practices are changing and expanding, creating a complex and ambiguous disciplinary landscape.

This directly impacts on the field of design education, calling for new, flexible models able to tackle future practitioners' needs, unknown markets, and emergent societal cultures. In response to design's uncertain contemporary identity, a Programme of Doctoral research was designed with the aim of identifying distinct approaches to postgraduate design education that could help to prepare future designers for what the thesis terms an Amplified Mindset of Design. This paper presents emerging findings from this Doctoral research, proposing and evidencing a conceptual framework that synthesises key movements within design, to bring clarity to the current discourse on emerging design practices. The conceptual framework of an Amplified Mindset of Design clusters this discourse into four groups: a world- and human-centred worldview; integrative behaviours, social skills, and visualisation. The paper closes by discussing this framework in relation to design education, suggesting the Amplified Mindset of Design as a tangible frame of reference to enable the development of design education. In this context it can be used as principles for pedagogical approaches, and as guidelines for curriculum design that fits our changing disciplinary practice within a complex global environment. Furthermore, the authors contend that there is potential to apply this framework outwith the field of design, proposing that other disciplines such as management, economics, and medicine could benefit from an educational experience that emphasises an Amplified Mindset. 
KEYWORDS: design education, emerging design practices, amplified mindset of design, conceptual framework, paradigm shift

\section{INTRODUCTION}

Change is a defining characteristic of design (Buchanan 1992; Heskett 2001; Yee, Jeffries \& Tan 2013). Its fragmented, organic, and shape-shifting nature (Myerson 1990 cited in Julier 2000) responds and adapts to social and economic contexts (Burns, Cottam, Vanstone \& Winhall 2006; Cooper \& Press 2003).

We live in a time of complexity (McArthur 2010) characterised by natural- and human-caused catastrophes, wars, global financial crisis (Fleming 2013; Imbesi 2011) and disruptive demographic changes (UNDESA 2004; Davies, Fidler \& Gorbis 2011). Research shows design practices that are rapidly changing, and expanding their territories of action (Cooper \& Press 2003; Julier 2000; Yee et al. 2013). Literature on this topic is prolific, offering a variety of views on the field's changes and expansion (see for example Burns et al. 2006; Friedman, Lou, Norman, Stappers, Voûte \& Whitney 2014; Imbesi 2011). This change and expansion can bring a sense of ambiguity to emerging design practices and cause confusion among design teams and their audiences. However, this ambiguity brings with it an emergent approach that is adapting and redefining itself, using Heskett's (2001) terms, to answer the world's growing complexity.

In response to this complex and emergent context, where design's contemporary identity is unclear, a Programme of Doctoral Research was designed. The Doctoral Research aims to identify distinct approaches to postgraduate design education, which help prepare future designers for what the thesis terms as an Amplified Mindset of 
Design-a mindset that reflects this complex, expanding, dynamic and emergent character of contemporary design practice.

This paper presents part of this Doctoral research, and is primarily focused on evidencing a conceptual framework of an Amplified Mindset of Design. By synthesizing the key movements within design, this paper aims to bring clarity to the current discourse on emerging design practices.

The paper will close by discussing this framework in relation to design education. It is hoped that this framework will provide a tangible frame of reference to enable discussion for the development of design education.

\subsection{Background}

Different interpretations and understandings of the activity of Design have been changing, and co-existing through time (Buchanan 1992). Figure 1, intends to offer a chronological scenario of successive additions and emerging changes in design with different layers - emerging outcomes and concerns, dominant paradigms, intervention sectors and higher education - culminating in a contemporary period that is complex and ambiguous. 


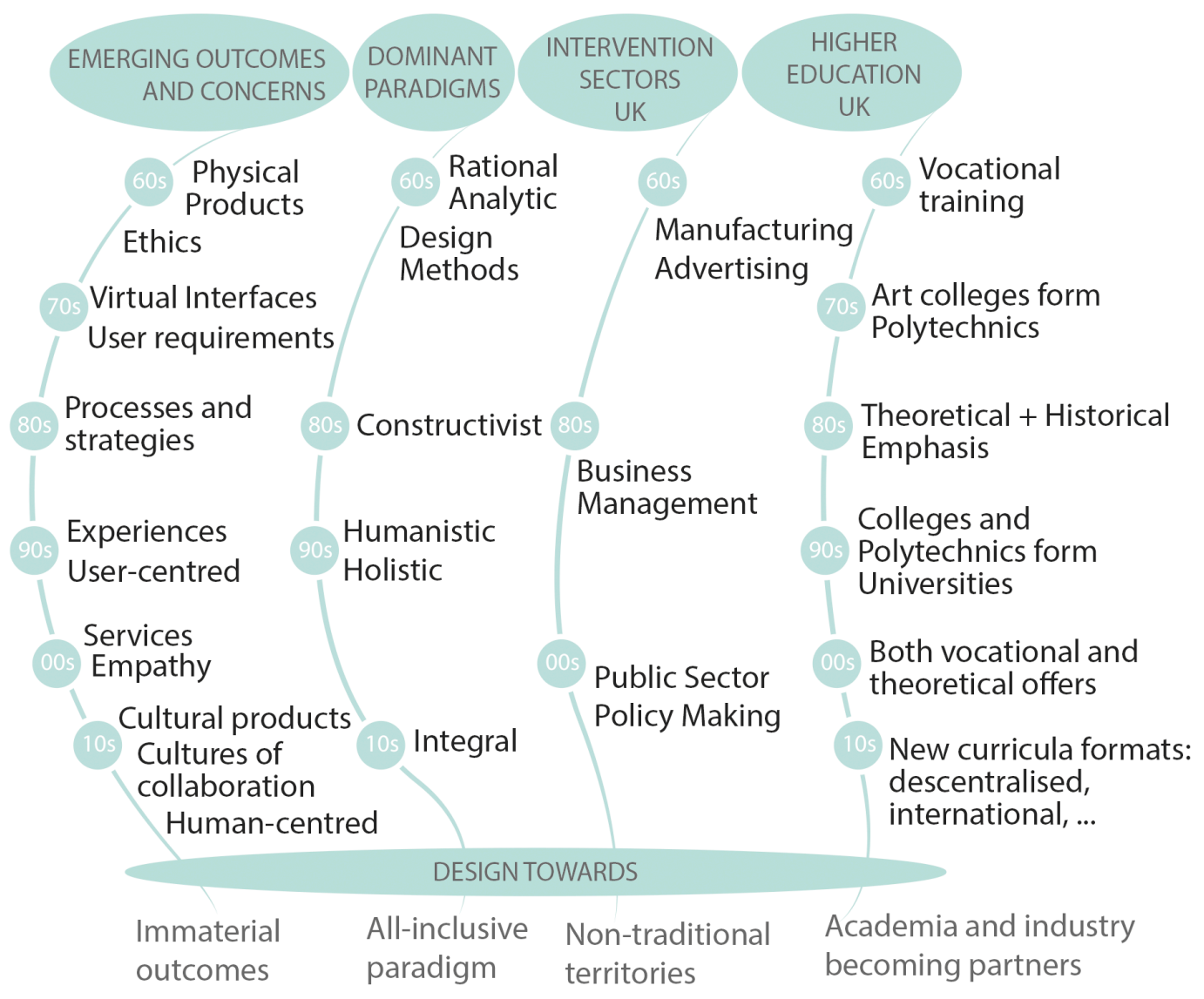

Figure 1 - Scenario emerging changes and successive additions in design.

Sources used to populate: Bridgstock 2013, Buchanan 1998, Burns et al. 2006, Cooper and Press 2003, Fleming 2013, Hobday et al. 2012, Imbesi 2012, Julier 2000, Murphy \& Baldwin 2012, Souleles 2013, Tschimmel 2014, Wood 2010.

To exemplify this scenario, emerging issues in design practices include a growing diversity of design's specialisations (Souleles 2013); the rise of immaterial outcomes such as the design of processes, services and cultures of collaboration (INDI 2015; Wood 2010a) informed by people instead of users (Imbesi 2012); interventions in wider territories (Bridgstock 2013; Cooper \& Press 2003; Imbesi 2012; Julier 2000; Yee et al. 2013) with political, economic and social concerns (Hobday, Boddington \& Grantham 2012); and closer work with academia (Buchanan 1998) that both responds and brings new insights to industry while exploring design challenges (Murphy \& Baldwin 2012; Teixeira 2013). 
Another aspect of this multi-layered chronology that reflects a general widening of design, is the paradigm shift from dominant rational worldviews to more pluralistic and inclusive ones (Bayazit 2004; Findeli 2001; Fleming 2013; Manzini 2013; Tschimmel 2014). The period dominated by a scientific approach linked with the manufacturing sector in the 1950s-60s (Bayazit 2004) was challenged by a more participatory approach to design in the 1970s concerned with suggesting alternative lifestyles to consumerist living (Armstrong, Bailey, Julier \& Kimbell 2014). In the 1980s a constructivist perspective emerged (Kazakçı 2013), focussing on notions of reflective conversations (Schön 1987), teamwork, negotiation and communication in design processes (Kazakçı 2013). This focus on reflection and social relations opened space for an Holistic and Humanistic paradigm in the 1990s (Tschimmel 2014; Heung Ryong 2007) expressed in a multidisciplinary approach to design (Heung Ryong 2007). Nowadays, Fleming (2013) refers to social responsibility, environmental awareness and empathy as distinctive aspects of current times as response to global complexity. Also discussed by Manzini (2013), these aspects reveal what Fleming (2013) refers to as integral paradigm, which can be said to be all-inclusive, encompassing rational and experiential aspects of design practices and human life. Furthermore, contemporary literature on design education reflects a desire for education models to change, and become dynamic to cope with future change (Findeli 2001; Gornick 2005; Martin 2010; McAra-McWilliam 2007; McWilliam \& Haukka 2008; Murphy \& Baldwin 2012).

The above is presented as a synthesis of the complex and ambiguous landscape that surrounds emerging design practices. In the next section, this paper will attempt to offer insights into the characteristics of these practices. 


\section{EMERGING CHANGES IN DESIGN PRACTICES}

A thorough literature review was undertaken to capture the dominant discourse on emerging design practices, by:

- Defining key emerging characteristics of design, in sub-section 2.1;

- Exploring views from literature on the designers' roles, in sub-section 2.2, and;

- Offering examples of emerging design specialisations to gain practical insight, in sub-section 2.3.

This literature review will now be outlined. At the end of this section, the paper will present elements (derived from the literature) which inform the creation of the conceptual framework of what we term an Amplified Mindset of Design.

\subsection{Integrative and Transformative}

The examination of the contemporary literature on design, has led to the identification of two design descriptors: integrative, and transformative.

It is, therefore, useful to define what this research takes these descriptors to mean. Here, the use of the word integral goes beyond the notion of inclusion, frequently inferred by the use of its verb form (integrate) where the resulting whole (Oxford English Dictionary Online - OED 2015) can still fail to provide an integral contribution if it follows a single intake on a given reality. However, to achieve a pluralistic position used to form a holistic understanding, this research follows the adjective form (integral) that refers to '[making] a whole complete' (OED 2015). As for the several meanings attributed to the word transformation by the OED (2015) this research's use of the term surpasses its synonym change, and resonates with its 
synonym metamorphosis and the act of 'complete change in character, condition, etc.' (OED 2015).

\section{Integrative}

This descriptor captures the multi-layered expansion of design illustrated in Figure 1 that suggests that design is entering an all-inclusive paradigm, exploring new territories of intervention and expanding its concerns.

Different terms from literature refer to design as a connector mainly between different types of knowledge (Buchanan 1998; Imbesi 2012), and different disciplines (Friedman et al. 2014). However, this notion of connection is taken further, towards integration, through cross-fertilisation (Imbesi 2012), translation, and negotiation activities between people and disciplines (Friedman et al. 2014). Bridgstock (2013) and Imbesi (2012) also discuss an emerging movement towards a transdisciplinary approach in design.

From the above, it can be said that emerging design practices sit and intervene in boundary 'spaces', and where encounters happen or are created between people and disciplines. Design as integrative can be characterised as pluralistic and holistic dealing with diverse contributions, and competing and paradoxical positions, to answer complex and interconnected challenges (Imbesi 2012).

\section{Transformative}

Research shows that considering design to be transformative can be interpreted as strategic and social.

Design's growing strategic influence in future shaping (Banerjee 2013; Murphy \& Baldwin 2012) is expressed in examples offered by Yee et al. (2013) for both private and public sectors, where designers' roles include coaching and mentoring (Teixeira 
2013), while working collaboratively in interdisciplinary teams to co-produce sustainable and transformative solutions for complex contexts (Banerjee 2013). It is a social mode of work (Manzini 2015) for (social) strategic purposes.

The social focus of a design approach for change and innovation, explored by Manzini (2015), is also referred to by Mendoza \& Matyók (2013) as introducing issues of empathy, and citizenship. In Hobday et al. (2012) we found the use of the term 'design sensing' (offered at the Weatherhead School of Management Conference in 2010) - which includes empathy, emotion, perception, and imagination - as a complement to design thinking, forming a design approach to wicked problems. From the previous we identify the presence of subjective aspects in design activities. Design as transformative can be characterised as a socially-engaged practice with strategic concerns about shaping futures. It includes subjective aspects such as empathy or emotions, and collaborative practices that impact designers and those involved in design processes at personal levels.

\subsection{Subjective levels of practice}

The emerging roles of designers are changing and leaving the prescriptive realm towards a more inclusive and collaborative one, imbued with the subjectivity common in human relationships. Contributions from literature show an inclination to explore subjective dimensions of the designers' roles as deeper levels of practice (McAraMcWilliam 2015). Figure 2, developed in the early stages of this $\mathrm{PhD}$ research, uses the Rose Window Model (RW) (McAra-McWilliam 2008) as a frame to organise contributions from literature on this topic. This model offers an integral perspective on the practice of design, dividing it into four dimensions (ways of seeing, being, thinking and making) that represent facets of the creative mind that co-exist as a 
whole (ibid.). The RW model represents an amplified take on design by integrating dimensions that are internal and external to the designer, both objective and subjective. To better explain the emerging focus on subjective aspects of design practice, we have superimposed a theoretical model from Integral Theory (EsbjörnHargens 2010) - 'Big Three' domains of reality: subjectivity, inter-subjectivity and objectivity.

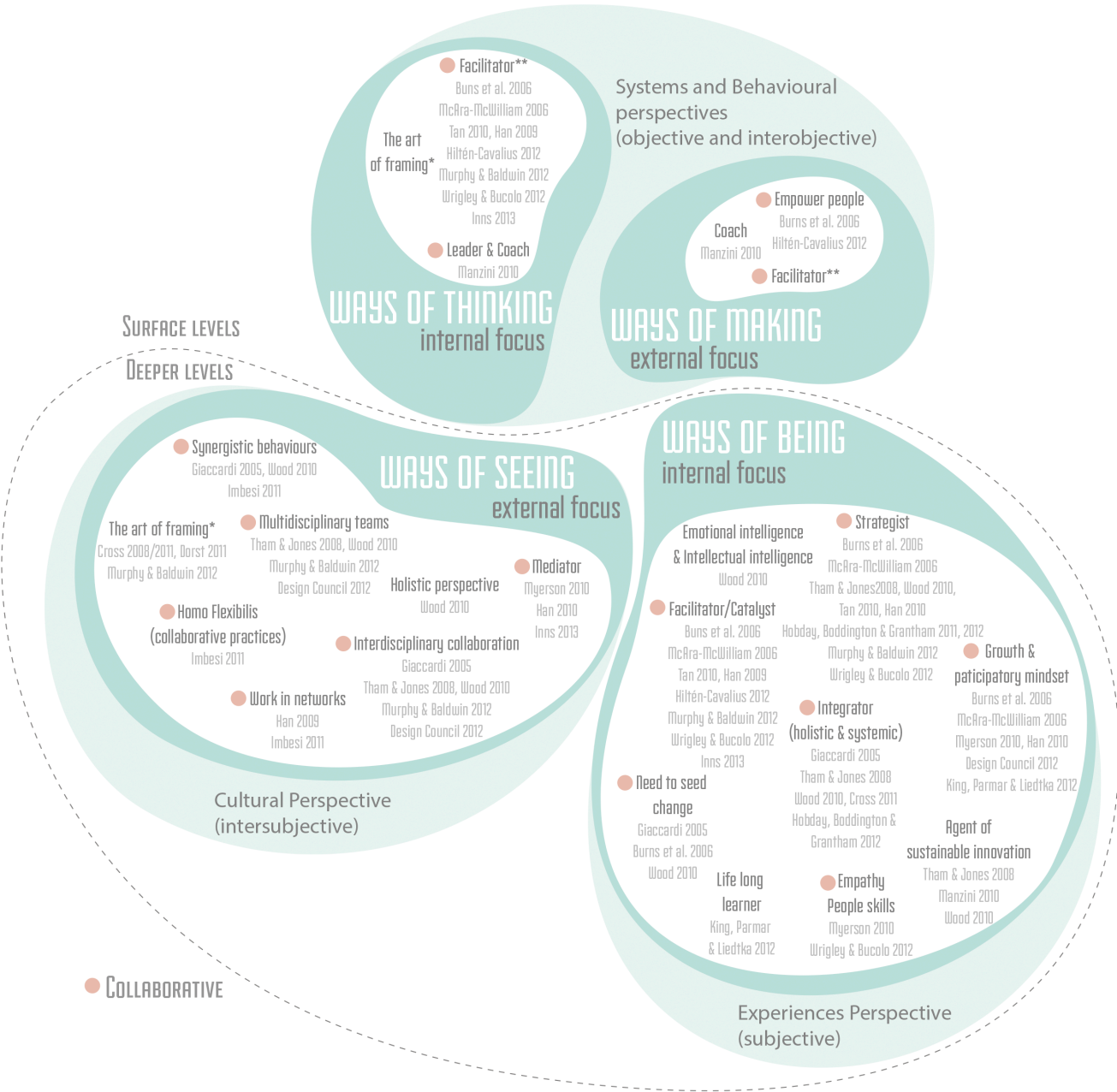

Figure 2 - Contemporary views on the designer's roles, framed using the four dimensions of the Rose Window Model by McAra-McWilliam (2008) and the Big Three dimensions of reality offered by Integral Theory (Esbjörn-Hargens 2010).

Sources used to populate: Burns et al. 2006, Cross 2011, Design Council 2012, Giaccardi 2005, Han 2010, Hiltén-Cavalius 2012, Hobday et al. 2011, Hobday et al. 2012, Imbesi 2011, Inns 2013, King et al. 2012, McAra-McWilliam 2008, McAra-McWilliam 2015, Manzini 2010, Murphy \& Baldwin 2012, Myerson 2010, Tham and Jones 2008, Wood 2010, Wrigley and Bucolo 2012. 
In Figure 2, the dimension Ways of Seeing represents an inter-subjective perspective referring to seeing and interacting with the world (McAra-McWilliam 2015).

Contributions from literature included in this quadrant reflect the designer's pluralistic approach that recognises the importance of collaboration between different disciplines, cultures and types of knowledge. Examples include a search to create synergies (Wood 2010a), interdisciplinary collaborations (Murphy \& Baldwin 2012), and networked modes of working (Imbesi 2011).

Ways of Being covers an experiential perspective where designers reflect on themselves, their roles and motivations attempting to define their identity (McAraMcWilliam 2015). Examples include the notions of being a strategist (Murphy \& Baldwin 2012), a facilitator (Burns et al. 2006), an integrator (Hobday et al. 2012), and a need to seed change (Wood 2010a).

Expressing an amplification of designers' roles towards cultural and experiential domains, Figure 2 highlights design practices heavily centred in collaboration, pluralistic, and with a focus on the designers identity. The latter demands from designers a personal willingness (or a way of being) to develop new skills and improve their awareness and reflexive ability, which can be seeded by design education.

\subsection{Emerging specialisations}

Practical examples of the aforementioned can be found in Metadesign (Wood 2010a) and Design Innovation (Cruickshank 2010) that show signs of an amplified perspective due to their interdisciplinary inclination, and disposition to reinvent their practices in comparison with more traditional design specialisations that present 
themselves with better defined boundaries, territories of intervention and types of outcomes.

\section{Metadesign}

As a practice that emerged in the 1980s, today's understanding of metadesign expanded the previous focus on [networked] information technologies (Giaccardi 2005) towards what Wood (2008) calls an 'augmented mode of practice' that goes beyond design, which this paper adheres to.

Advocating for a holistic mindset (Wood 2007) and emerging, non-hierarquical processes (Tham \& Jones 2008; Wood 2010b), a metadesign approach seeks to promote a more sustainable mode of living (Tham \& Jones 2008) through interdisciplinary and multi-layered collaborations (Alexiou, Jeffrey \& Zamenopoulos 2010; Tham \& Jones 2008; Wood 2008; Wood 2010a). Rather than artefacts or fixed content, metadesign solutions are presented as open-ended structures (Giaccardi 2005) that allow systems to evolve further (Fuad-Luke 2007; Giaccardi 2005; Wood 2008). This approach acts at a fundamental level, more concerned with principles of practice (Wood 2010a).

\section{Design Innovation}

Since the 1990s, design innovation has been expanding its interventions from a differentiation role within the manufacturing industry and technology (Walsh 1996), to a strategic role in business and management (Borja de Mozota 2002; Ramlau 2004). Design innovation, within the context of this paper, is currently showing a wider social and cultural perspective of innovation by including non-economic concerns and intangible aspects (Rusk 2011; Manzini 2015) with a stronger focus on processes as artifacts rather than end-artifacts alone (Manzini 2013; Siodmok 2013; 
Teixeira 2013). Challenging to define (Cruickshank 2010), design innovation can be said to be 'involved in understanding and articulating complex social interactions between multiple stakeholders engaged in design inquiry through both research and professional practice.'(INDI 2015: 02)

As a research-based practice design innovation can be said to offer a practical approach that seeds agency and a self-learning ecosystem (Lockwood, Smith \& McAra-McWilliam 2012).

\section{Metadesign \& Design Innovation}

Both specialisations share a networked approach and collaborative qualities seeking integration at human-, organisational-, and disciplinary-levels, which is a complex task suitable to the complexity of contemporary challenges. Their strategic and transformational concerns are not only oriented towards their audiences but are also reflected in a disposition for continuously reinventing their practices to adapt to the referred complexity. However, a metadesign approach shows a deeper focus on principles for practice and on processes, while design innovation whilst sharing the same concerns provides a more practical approach informed by design's hard skills and aesthetical care. These complementary specialisations reflect the course that emerging design practices are taking and can inform a distinct approach to design education.

In this section, we have described design as an integrative and transformative practice that reflects an expansion towards a more holistic and inclusive perspective of design. The exploration of subjective levels of practice showed an expansion from a prescriptive practice towards a collaborative and social practice that influences 
designers to personally explore and reflect on their identity. Metadesign and Design Innovation are examples of 'wider' emerging specialisations with adaptive, collaborative and networked ways of working, and a social and sustainability strategic focus.

Figure 3 shows how the discourse offered in this section was used to create a conceptual framework that reflects the notion of Design as an "Amplified Practice", which will be explained more fully in the next section. The arrows in Figure 3 highlight the main influence of each topic in the creation of groups, although we recognize that there are overlaps between groups, such is the nature of an interconnected system.

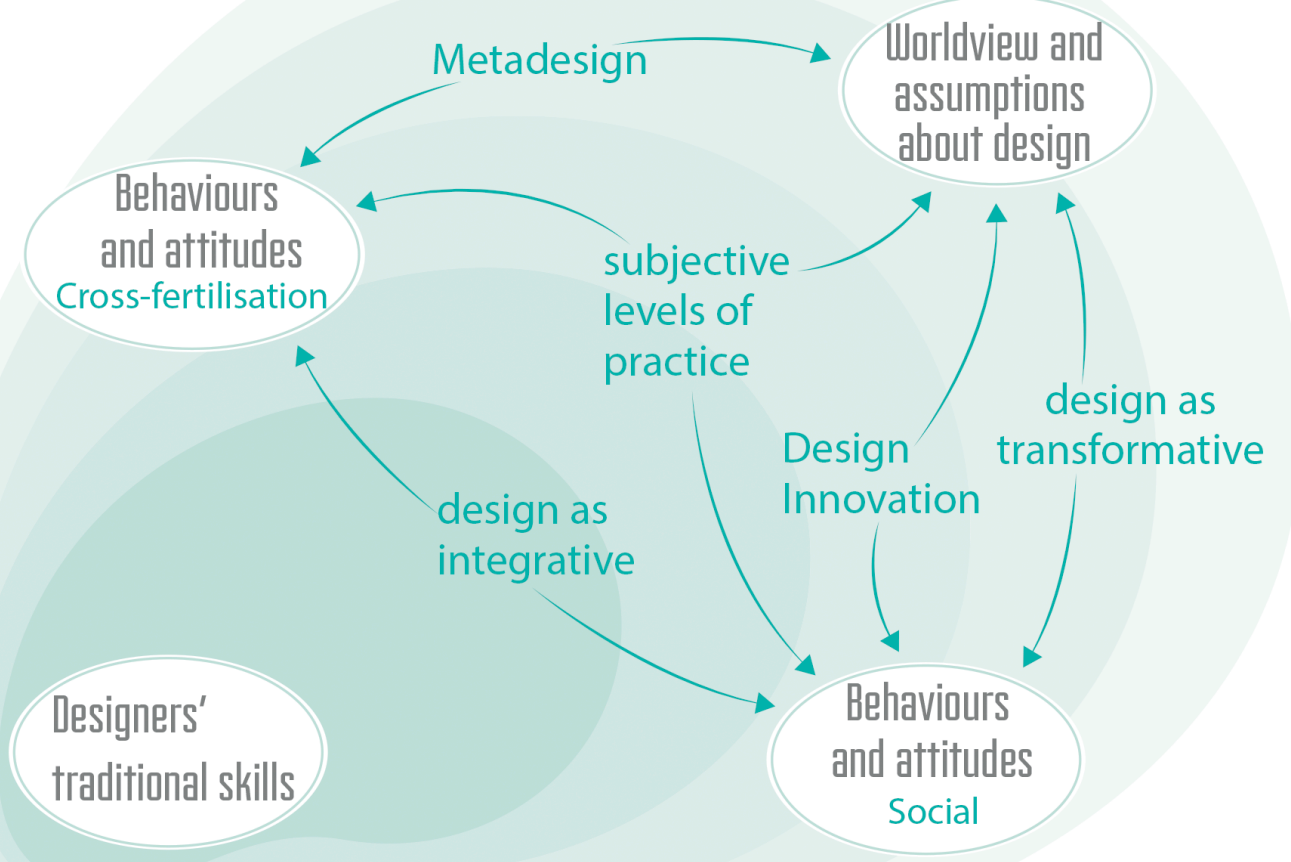


Figure 3 - The main influence of key topics from section 2 in the creation of groups that will inform the creation of a conceptual framework of an Amplified Mindset of Design.

By: Moreira 2016

\section{AMPLIFIED MINDSET OF DESIGN}

\subsection{Naming a phenomenon}

The conceptual framework of an Amplified Mindset of Design is still under development, and can be found in a previous publication (Moreira 2015) as amplified practice of design (rather than mindset), produced in earlier stages of this research. The change from practice to mindset reflects a wider understanding of design as more than an activity or a profession, including a worldview, an attitude and a way of thinking about design.

The term amplified was purposely chosen, to reflect the expansion of design's territories of intervention and concerns, and the inclusiveness of a pluralistic approach. To address the intangible aspects of emerging design practices, this term was also described using the metaphor of audio waves that invisibly vibrate in the atmosphere increasing intensity and reach. We also used the metaphor of a sonar to reflect the reciprocity of design interactions as a signal that is emitted and that reflects back in multi-directions with more information, and unpredictable reach. An Amplified Mindset of Design intends to capture the contemporary, emerging approach that designers adopt in response to, and to work with(in) the world's growing complexity. This framework clusters the discourse on emerging design practices in four groups: (1) a world- and human-centred worldview; (2) integrative behaviours, (3) social skills, and (4) visualisation. 


\subsection{A conceptual framework in progress}

The following findings are based on this study's literature review and early fieldwork. Figure 4 illustrates the conceptual framework of an Amplified Mindset of Design that in the future of the doctoral programme will be used to inform a curricular approach to design education. The 'Visualisation' group represents the designers' traditional skills, and it informs all other aspects of the framework. From this group we can amplify the designers' activity towards an attitude and behaviors that reflect what designers do, which includes 'Integrative Behaviours' that demand for the mastering of 'Social Skills'. Lastly, we have a 'Human- and World-Centred' worldview and a set of assumptions about design that represent a foundation for the remaining groups. Figure 4 offers these as four separate groups, although they overlap and influence each other.

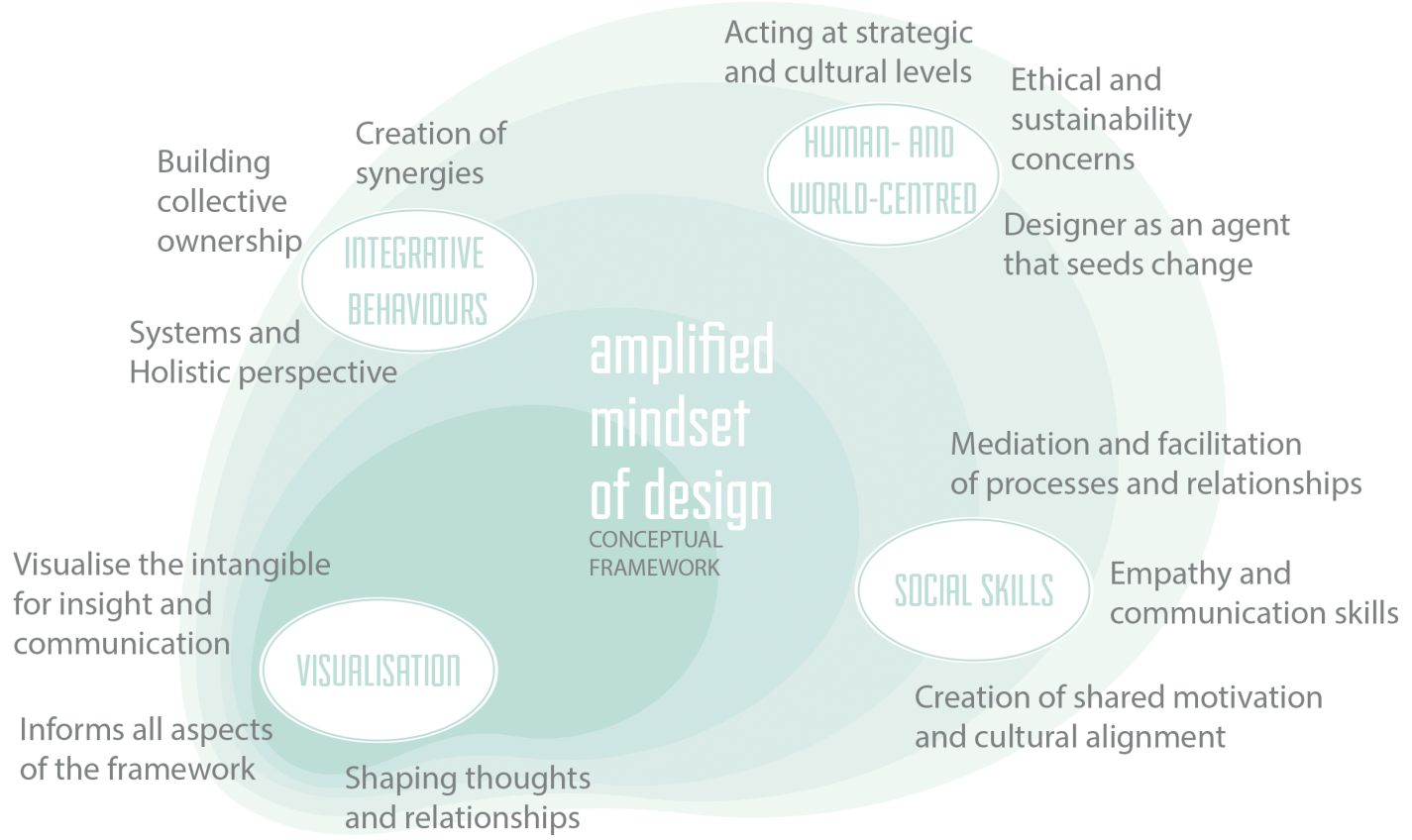


Figure 4 -Conceptual Framework of an Amplified Mindset of Design.

Sources: Banerjee 2013, Buchanan 1998, Burns et al. 2006, Cross 2011, DeKay 2011, Fleming 2013, Friedman et al. 2014, Giaccardi 2005, Hobday et al. 2012, Han 2009, Imbesi 2011, Imbesi 2012, INDI 2015, Inns 2013, Lawson \& Dorst 2009, McAra-McWilliam 2008, Manzini 2015, Mendoza \& Matyók 2013, Michlewski 2015, Murphy \& Baldwin 2012, Myerson 2010, Rusk 2011, Teixeira 2013, Tham \& Jones 2008, Wood 2007, Wood 2010a, Wrigley \& Bucolo 2012.

\section{Human- and world-centred strategic concerns}

Within the aforementioned global context in which design operates, this element recognises that society is changing its concerns and behaviours. It can be interpreted as a worldview that expands on user-centred focus towards a focus on human beings as part of the natural, economic and social worlds. By acknowledging the interplay of different dimensions and components it seeks sustainability in processes and solutions. Achieving more social and sustainable solutions is recognised as an important role of designers (Manzini 2013; Fleming 2013; DeKay 2011; Tham \& Jones 2008; Wood 2010b). This can be attained through the designers' strategic role (Lawson \& Dorst 2009; Murphy \& Baldwin 2012; Yee et al. 2013) as agents that seed change (Manzini 2010) with strong ethical and sustainability concerns (Imbesi 2012; Gamman \& Thorpe 2006; Wood 2010b).

\section{Integrative behaviours}

This element refers to an all-encompassing approach that seeks cross-fertilisation and the exploration of boundary spaces. These integrative behaviours are informed by a systems and a holistic perspective (Giaccardi 2005; Imbesi 2011; Hobday et al. 2012; Wood 2010a; Lawson \& Dorst 2009; Fleming 2013). Through the creation of synergies (Wood 2010a) designers (a) connect knowledge and disciplines (Buchanan 1998; Bridgstock 2013; Imbesi 2012; Yee et al. 2013), and (b) negotiate between people and disciplines (Friedman et al. 2014) by (c) welcoming objective and 
subjective perspectives (Wood 2010a; Hobday et al. 2012), and (d) their personal development through their profession (Lawson \& Dorst 2009; McAra-McWilliam 2010, Wood 2010b). This category also includes the notion of creating collective ownership of design solutions (Sangiorgi 2011; Wood 2010a) that results from integrative behaviours.

\section{Mastering social skills}

This element arises from the growth of interdisciplinary and co-design approaches in design. The designers' set of skills identified by Cooper \& Press (2003) include the notion of designers as empathisers and social initiators also addressed by Myerson (2010) and Mendoza \& Matyók (2013) as skills to be developed by designers. Interpersonal skills as part of the designers' culture (Michlewski 2015) are also referred to in literature (Han 2009; Inns 2013; Wood 2010a), with a particular focus on the mediation and facilitation of processes and relations, and the creation of shared motivation and cultural alignment between stakeholders. Moreover, the subjectivity of social skills asks for a more intuitive and emotional reasoning to complement the dominant intellectual and objective reasoning in design processes (Dorst 2011; Hobday et al. 2012; Wood 2010).

\section{Visualisation}

This element refers to the strategic use of 2-D and 3-D visualisation techniques to foster dialogue and insight. In particular it refers to the visualisation of the intangible (for example experiences, cultures, and complex social systems) to improve processes of shaping thoughts and relationships (see for example Lawson \& Dorst 2009; Inns 2013; Findeli 2001; Abbs 2003; Manzini 2013). Through the creation of visual-sense designers bring new forms of understanding, discovery and critique (Lawson \& 
Dorst 2009). By manipulating information, Manzini (2013) argues that designers should move from visualisation as display of information to visualisation for visioning where the designers' perspectives come into play through an aesthetic dimension that steers social conversations.

\section{WHAT DOES THE CONCEPTUAL FRAMEWORK MEAN FOR DESIGN EDUCATION?}

This paper has developed a conceptual framework which communicates the elements of an Amplified Mindset of Design, which can contribute to the debate on how we develop more flexible approaches and models in design education (Findeli 2001; Gornick 2005; Martin 2010; McWilliam \& Haukka 2008; Murphy \& Baldwin 2012) to answer to the future professionals' needs, unknown markets, and emerging societal cultures (McArthur 2010).

There are perspectives on design education that emphasise thinking over methods (Davies et al. 2011; Tschimmel 2006) and providing the learners with tools to gather and adapt knowledge instead of teaching knowledge that soon will be obsolete (Press 2013). Findeli (2001) advocates for a focus in transforming the learners' view of the world and developing individual ethical awareness. This reflection on design education aligns with Maclellan's (2015) understanding of teaching in higher

education as '[enabling] learners to acquire knowledge and to use such knowledge at different time points, in different contexts and for different purposes from those in which the knowledge was first acquired.' (ibid., 172).

Research also shows a common understanding on the need to embrace 
interdisciplinary approaches in design education (Gornick \& Grout 2008; McArthur 2010; Murphy \& Baldwin 2012; Young 2013) and a focus on developing the learners' confidence and knowledge of their professional contribution (Teixeira 2013; Young 2013). Murphy \& Baldwin (2012) add to the previous, the principles of emergence and integration as guidelines for design educators to consider while assisting their students in the development of amplified design roles. Furthermore, McArthur (2010) reflects on the need to consider the different cultures that increasingly form learners' cohorts, and Mendoza \& Matyók (2013) argue for international models of design education based on empathic behavior with transformational concerns rather than 'production, reproducibility and ownership' (ibid., 213). By its account, this social and cultural diversity in design education, and the social direction that design is taking asks for design education to include the development of social skills in learners (Murphy \& Baldwin 2012; Wrigley \& Bucolo 2012).

As design education moves towards a networked understanding of different spheres of knowledge and different levels of interaction, it is relevant to mention the need for a sociological approach to education, that according to Trowler (2005) sits unexplored between more established approaches such as phenomenography and educational macro approaches. As argued by Trowler (2005) this approach considers learning as placed not only in the learners' mind but also in 'social participation and dialogue'. This research's approach to postgraduate design education for an Amplified Mindset of Design can be placed within Trowler's sociological approach to education (ibid.). As a framework, an Amplified Mindset of Design constitutes one possible way of responding to the identified needs for design education. It can be used as principles for pedagogical approaches to design education, and as guidelines for curricular practices and curriculum design to fit our disciplinary context of change, and 
global complexity. This framework could also be used outwith design education, namely in technology and executive education, due to the growing recognition of design as a strategic driver for business and technology industries (Maeda 2016).

\section{CONCLUSION}

This paper has focused on investigating emerging design practices, attempting to bring clarity to an ambiguous disciplinary scenario that is changing and expanding to answer the complexities of current times. A conceptual framework of an Amplified Mindset of Design was built to reflect the emerging discourse that suggests a more inclusive and pluralistic understanding of design, and the expansion of practices towards collaboration, and social engagement. As a work in progress, and part of Doctoral research, this framework clusters the current design discourse in four groups: (1) a world- and human-centred; (2) integrative behaviours, (3) social skills, and (4) visualisation.

Aspiring to be a tangible frame of reference to enable the development of design education, which is debating the need for new models, beyond this paper, this conceptual framework will be used as a guide to develop a postgraduate curricular approach that fits our disciplinary context of change, and global context of complexity.

Furthermore, the authors contend that there is potential to place this framework outwith the field of design, and that other disciplines such as management, economics, and even medicine could benefit from an educational experience that emphasises an Amplified Mindset. 


\section{ACKNOWLEDGEMENTS}

This research is supported by FCT-Fundação para a Ciência e a Tecnologia (QREN,

POPH e Fundo Social Europeu), Portuguese Ministry for Education and Science.

\section{REFERENCES}

Abbs, P. (2003) Against the flow: Education, the arts, and postmodern culture. London: RoutledgeFalmer.

Alexiou, K., Jeffrey, J. \& Zamenopoulos, T. (2010) Embracing complexity in Design: emerging perspectives and opportunities, in T. Inns [Ed.] Designing for the 21 st century, Volume 2: Interdisciplinary methods and findings. Farnham: Gower, pp. 87-100.

Armstrong, L., Bailey, J., Julier, G. \& Kimbell, L. (2014) Social Design Futures - HEI Research and the AHRC. [report] Brighton: University of Brighton.

Banerjee, B. (2013) The identity crisis of designers, in J. Yee, E. Jefferies \& L. Tan [Eds] Design Transitions. Amsterdam: Bis Publishers, pp. 192-5.

Bayazit, N. (2004) Investigating Design: A Review of Forty Years of Design Research, Design Issues, Vol. 20, No. 1, pp. 16-29.

Borja de Mozota, B. (2002). Design and competitive edge: A model for design management excellence in European SMEs, Design Management Journal - Academic Review, Vol. 2, pp. 88-103.

Bridgstock, R. (2013) Professional Capabilities for Twenty-First Century Creative Careers: Lessons from Outstandingly Successful Australian Artists and Designers, The International Journal of Art \& Design Education, Vol. 32, No. 2, pp. 176-89.

Buchanan, R. (1992) Wicked Problems in Design Thinking, Design Issues, Vol. 8, No. 2, pp. 5-21.

Buchanan, R. (1998) Education and Professional Practice in Design, Design Issues, Vol. 14, No. 2, pp. 63-6.

Burns, C., Cottam, H., Vanstone, C. \& Winhall, J. (2006) Red paper 02 Transformation Design . (online) Available at:

http://www.designcouncil.info/mt/red/transformationdesign/transformationdesignfinaldraft.pdf (accessed 31st January 2014).

Cooper, R. \& Press, M. (2003) The design experience: the role of design and designers in the 21st century. Aldershot: Ashgate.

Cross, N. (2011) Design Thinking. Oxford: Berg.

Cruickshank, L. (2010) The Innovation Dimension: Designing in a Broader Context, Design Issues, Vol. 26, No. 2, pp. 17-26. 
Davies, A. Fidler, D. \& Gorbis, M. (2011) Future skills 2020 report. Palo Alto: Institute for the future for the University of Phoenix Research Institute.

DeKay, M. (2011) Integral sustainable design: a transformative perspective. London: Earthscan.

Design Council (2012) Changing Behaviour by Design - Report. [pdf] Available from: http://www.designcouncil.org.uk/knowledge-resources/report/changing-behaviour-design. [Acessed: 27 January 2014].

Dorst, K. (2011) The core of 'design thinking' and its application, Design Studies, Vol. 6, No. 32, pp. 521-32.

Esbjörn-Hargens, S. (2010) An overview of Integral Theory, in S. Esbjörn-Hargens [Ed] Integral theory in Action. New York: Suny Press, pp. 33-61.

Findeli, A. (2001) Rethinking Design Education for the 21st Century: Theoretical, Methodological, and Ethical Discussion, Design Issues, Vol. 17, No. 1, pp. 5-17.

Fleming, R. (2013) Design education for a sustainable future. New York: Routledge.

Friedman, K., Lou, Y., Norman, D., Stappers, P.J., Voûte, E. \& Whitney, P. (2014) DesignX: A future path for design. (online) Available at: http://www.jnd.org/dn.mss/designx_a_future_pa.html (accessed 3rd December 2014).

Fuad-luke, A. (2009) Design Activism. A beautiful strangeness for a sustainable world. London: Earthscan.

Gamman, L. \& Thorpe, A. (2006) What is Socially Responsive Design: a theory and practice review, in Design and Research Society International Conference -Wonderground. Lisbon, 1st-4th November 2006 (online) Available at: https://www .academia.edu/4287710/what_is_socially_responsive_design__a_theory_and_practice_review (accessed 3rd March 2014).

Giaccardi, E. (2005) Metadesign as an emergent design culture, Leonardo, Vol. 38, No. 4, pp. $342-9$.

Gornick, N. (2005). Education for metadesign. (online). Available at: attainable-utopias.org http://attainable-utopias.org/tiki/education-for-metadesign (accessed 4th February 2014).

Gornick, N. \& Grout, I. (2008) A dialogue on the future of design education, in Changing the Change Conference Proceedings. Torino, 10th-12th July. Torino: Allemandi Conference Press. [no pagination].

Han, Q. (2009) Managing stakeholder involvement in service design, in DeThinkingService RethinkingDesign - First Nordic Conference on Service Design and Service Innovation. Oslo, 24th26th November. [no pagination].

Han Q. (2010) Practices and Principles in Service Design: stakeholder, knowledge and Community of Service, $\mathrm{PhD}$ thesis, University of Dundee, Dundee, UK.

Heskett, J. (2001) Past, Present, and Future in design for Industry, Design Issues, Vol. 17, No. 1, pp. 18-26.

Heung Ryong, W. (2007) A Holistic Experiential Approach to Design Innovation, in IASDR Conference: Emerging Trends in Design Research. Hong Kong, 12th-15th November. [no 
pagination]. (online) Available at: http://www.sd.polyu.edu.hk/iasdr/proceeding/ (accessed 4th January 2015)

Hobday, M. Boddington, A. \& Grantham, A. (2011) An Innovation Perspective on Design: Part 1. Design Issues, Vol. 27, No. 4. p. 5-15.

Hobday, M. Boddington, A. \& Grantham, A. (2012) An innovation perspective on design: part 2, Design Issues, Vol. 28, No. 1, pp. 18-29.

Hyltén-Cavalius, S. (2012) Shifting Mindset: Towards sustainability at Linnaeus University Design Programmes, in Cumulus Working Papers - Projecting Design. Santiago de Chile, November. Santiago do Chile: School of Design Duoc UC, Alto University. pp.24-9.

Imbesi, L. (2011) Design comes out of industry: new critical approaches for design in the economy of post- production, in Cumulus Working Papers. Publication series G. Paris-Sèvres, May. Paris: School of Art and Design, Aalto University. pp. 36-43.

Imbesi, L. (2012) From the Culture of Project to Spread Creativity: Mutations of design as a profession in the society of knowledge, in Design Research Society Conference Proceedings. Volume 3. Bangkok, 1st-4th July. Bangkok: Design Research Society. pp. 776-790.

INDI- Institute of Design Innovation. (2015) Masters of Research: The Glasgow School of Art. [Email] Message to: PHD-DESIGN JISCMail. 13th October 2015.

Inns, T. (2013). Theaters for design thinking, Design Management Review, Vol. 24, pp. 40-7.

Julier, G. (2000) The culture of design. London: Sage.

Kazakç1, A. (2013) On the imaginative constructivist nature of design: a theoretical approach, Research in Engineering Design, Vol. 24, No. 2. pp.127-145.

King, A., Parmar, B. and Liedtka, J. (2012) Mapping the Design Mind, in Leading Innovation through Design: Proceedings of the DMI 2012 International Research Conference. Boston, 8th-9th August. Boston: Design Management Institute.pp. 117-122.

Lawson, B. \& Dorst, K. (2009) Design Expertise. Oxford: Elsevier.

Lockwood, J., Smith, M. \& McAra-McWilliam (2012) Work-well: Creating Cultures of Innovation through Design, in Leading Innovation through Design: Proceedings of the DMI 2012 International Research Conference. Boston, USA, 9th-12th August. Boston: Design Management Institute. pp. 747-57.

Maclellan, E. (2015) Updating understandings of 'teaching': taking account of learners' and teachers' beliefs, Teaching in Higher Education, Vol. 20, No. 2, pp. 171-182.

Maeda, J. (2016) Design in Tech Report. (online) March 2016. Available at: http://www.kpcb.com/blog/design-in-tech-report-2016 (accessed 20th March 2016) 
Manzini, E. (2010) Social innovation and design. How designers can trigger and support sustainable changes, in Cumulus Working Papers. Publication Series G. Shanghai, October. Shanghai: School of Art and Design, Aalto University. pp. 9-14.

Manzini, E. (2013) The softer qualities that designers bring, in J. Yee, E. Jefferies \& L. Tan [Eds] Design Transitions. Amsterdam: Bis Publishers, pp. 212-15.

Manzini, E. (2015) Design when everybody Designs. Massachusetts: MIT Press.

Martin, P. (2010). Making space for creativity. Brighton: University of Brighton.

McAra-McWilliam, I. (2007). Impossible Things? Negative Capability and The Creative imagination, in Creativity or Conformity? Building Cultures of Creativity in higher Education. Cardiff, 8th-10th January. Cardiff: University of Wales Institute. [no pagination].

McAra-McWilliam, I. (2008) Design Transformations (opening keynote presentation, in The 26th Annual CHI Conference on Human Factors in Cumputing Systems. Florence, Italy, 05th-10th April. (online) Available at: https://www.youtube.com/watch?v=JT_Jc5d-81M (accessed 28th March 2016).

McAra-McWilliam, I. (2010) The Rose Window: Design and the Creative Imagination. Unpublished.

McAra-McWilliam, I. (2015) The Rose Window [Lecture]. Studio 2. The Glasgow School of Art, Institute of Design Innovation, Reid Building Auditorium, 13th April 2015.

McArthur, I. (2010) Creating culturally adaptive pedagogy, in Cumulus Conference Proceedings: young creators for better city and better life. Shanghai, 6th-10th September. Shanghai: School of Art and Design, Aalto University. pp. 70-76.

McWilliam, E. \& Haukka, S. (2008) Educating the creative workforce: new directions for twenty-first century schooling, British Educational Research Journal, Vol. 34, No. 5, pp. 651-666.

Mendoza, H. R. \& Matyók, T. (2013) Designing Student Citizenship: Internationalised Education in Transformative Disciplines, The International Journal of Art \& Design Education, Vol. 32, No. 2, pp. 215-225.

Michlewski, K. (2015) Design Attitude. Farnham: Ashgate.

Moreira, M. (2015) Distinct approaches to design education: preparing future designers for an amplified practice of design, in NORDES 2015: Design Ecologies. Stockholm, 7th-10th June. Sweden: Nordic Design Research. [no pagination] (online) Available at: http://www.nordes.org/opj/index.php/n13/article/view/448/420 (accessed 6th October 2015).

Murphy, E \& Baldwin, J. (2012) Learning to Practice: Nurturing Client Business in Design Education, in Leading innovation through design: proceedings of the DMI 2012 International Research Conference. Boston, 9th-12th August. Boston: Design Management Institute. pp. 90-103.

Myerson, J. (2010) A landscape of change for design challenges, in Cumulus Working Papers. Publication Series G. Shanghai, October. Shanghai: School of Art and Design, Aalto University. pp. $18-21$

OED-Oxford English Dictionary Online. (2015) (online) Available at: http://www.oed.com/. 
Press, M. (2013) The new 'can-do' design generation, in J. Yee, E. Jefferies \& L. Tan [Eds] Design Transitions. Amsterdam: Bis Publishers, pp. 200-3.

Ramlau, U. H. (2004). In Denmark, Design Tops the Agenda, Design Management Review, Vol. 15, No. 4.pp. 48-54.

Rusk, M. (2011) New Ways of Knowing: Strategic Design for Social and Economic Innovation, in IED Design Business Conference, Processes and Models of Designing Business. Provocation Statement. Instituto Europeo di Design - IED, Barcelona, 1st October. p. 3. [conference contribution] (online) Available at: http://www.designbusinessconference.com/the-conference/provocations/ (accessed 31st January 2014).

Sangiorgi, D. (2011) Transformative services and transformation design, International Journal of Design, Vol. 5, No. 2, pp. 29-40.

Schön, D. (1987) Educating the Reflective Practitioner. San Francisco: Jossey-Bass Publishers.

Siodmok, A. (2013) Design's contribution to social policy, in J. Yee, E. Jefferies \& L. Tan [Eds] Design Transitions. Amsterdam: Bis Publishers, pp. 220-3.

Souleles, N. (2013) The Evolution of Art and Design Pedagogies in England: Influences of the Past Challenges for the Future, The International Journal of Art \& Design Education, Vol. 32, No. 2, pp. 243-255.

Teixeira, C. (2013) Design knowledge in emerging markets, in J. Yee, E. Jefferies \& L. Tan [Eds] Design Transitions. Amsterdam: Bis Publishers, pp. 208-211.

Tham, M. \& Jones, H. (2008) Metadesign tools: designing the seeds for shared process of change. (online) Available at: http://attainable-utopias.org/tiki/academicpapers (accessed 4th February 2014).

Trowler, P. (2005) A sociology of teaching, learning and enhancement: improving practices in higher education, Revista de Sociologia, Vol. 76, pp. 13-32.

Tschimmel, K. (2006) Let students think about their thinking in design. A constructivist approach, inEnhancing curricula: contributing to the future, meeting the challenges of the 21st century in the disciplines of art, design and communication: Proceedings of the Centre for Learning and Teaching in Art and Design (cltad) 3rd International Conference. London, 9th-10th November. London :

University of the Arts London, cltad. pp. 655-668.

Tschimmel, K. (2014) Designer ou Design Thinker: Reflexão sobre Conceitos_1 ${ }^{\mathrm{a}}$ parte. PLI*ARTE \& DESIGN, Vol. 5, Matosinhos: Edições ESAD, pp. 159-165.

UNDESA. (2004) Proceedings of the United Nations expert meeting on world population in 2300. United Nations headquarters New York. March 2004. New York: United Nations.

Walsh, V. (1996). Design, innovation and the boundaries of the firm, Research Policy, Vol. 25, No. 4. pp. 509-529.

Wood, J. (2007) Win-Win-Win-Win: Synergy Tools for Metadesigners, in T. Inns [Ed.] Designing for the 21st Century: interdisciplinary questions and insights. Aldershot: Gower, pp. 114-128. 
Wood, J. (2008) Changing the Change: a fractal framework for metadesign. (online) Available at: http://attainable-utopias.org/tiki/AcademicPapers (accessed 4th February 2014).

Wood, J. (2010a) Co-designing Team Synergies within Metadesign, in Cumulus Conference Proceedings: young creators for better city and better life. Shanghai, 6th-10th September. Shanghai: School of Art and Design, Aalto University. pp. 165-172.

Wood, J. (2010b) Metadesign: The Design Practice that Designs Itself, in T. Inns [Ed.] Designing for the 21st century, Volume 2: interdisciplinary methods and findings. Farnham: Gower, pp. 101-115.

Wrigley, C. \& Bucolo, S. (2012) I just want to design a sexy flying car! Teaching design-led innovation to designers, in Cumulus Working Papers. Santiago de Chile, November. Santiago de Chile: School of Art and Design, Aalto University. pp. 71-6.

Yee, J., Jefferies, E. \& Tan, L. (2013) Design Transitions. Amsterdam: Bis Publishers.

Young, R. (2013) Design's increasing capacity to act as a mediating discipline, in J. Yee, E. Jefferies \& L. Tan [Eds] Design Transitions. Amsterdam: Bis Publishers, pp. 184-7. 